Proceedings

\title{
Carbon-Based Nanomaterials for Electrochemical- Disinfection Applications ${ }^{\dagger}$
}

\author{
Nandini Dixit and Swatantra P. Singh * \\ Environmental Science and Engineering Department, Mumbai, India; email1@gmail.com \\ * Correspondence swatantra@iitb.ac.in, Tel.: +022-2576-7859 \\ + Presented at the 2nd International Online-Conference on Nanomaterials, 15-30 November 2020; \\ Available online: https://iocn2020.sciforum.net/.
}

Published: 15 November 2020

\begin{abstract}
Carbon-based materials have shown captivated applications in water-purification technology, and one of them includes disinfection. The microbial safety of the water has remained a challenging task despite being equipped with many technologies. Traditional disinfection methods, including chlorination, ozonation, and ultraviolet radiation, suffer limitations in high chemical dosage and cost. The viability of these processes gets hindered when the generation of disinfection-by-products comes into play, which exhibits carcinogenic activity [1]. Electrochemical disinfection is an excellent technology for its non-hostile operation, low cost, and residual effect [2]. However, it still suffers from low oxygen overvoltage, charge reversibility, and lower current efficiencies. The mediation of nanomaterials enhances its capability due to their large surface area. Carbon-based nanomaterials, due to their nanometer size, possess excellent surface properties along with high conductivity, which makes them a versatile agent for electrochemical disinfection-based applications [3]. The nanomaterials, including graphene, carbon nanotubes, fullerenes, nanodiamonds, have shown excellent antimicrobial properties over a broad range of microbes. Their action ranges from cutting, penetration to the generation of reactive oxygen species (ROS). LaserInduced-Graphene (LIG), a recently discovered 3-D nanomaterial, had shown excellent surface properties and conductivity, which, when employed for electrochemical disinfection applications as membrane filters, manifested positive results against bacteria [4]. Its facile one-step approach of preparation by laser scribing on any carbonaceous surface makes it a versatile material for longterm disinfection applications. In this work, significant challenges with the conventional disinfection systems are highlighted and how electrochemical disinfection techniques could overcome that with the intervention of carbon-based nanomaterials.
\end{abstract}

Keywords: Laser-Induced Graphene; electrochemical disinfection; carbon-based nanomaterials

\section{References}

1. Bull, R.J.; Reckhow, D.A.; Li, X.; Humpage, A.R.; Joll, C.; Hrudey, S.E. Potential carcinogenic hazards of non-regulated disinfection by-products: Haloquinones, halo-cyclopentene and cyclohexene derivatives, Nhalamines, halonitriles, and heterocyclic amines. Toxicology 2011, 286, 1-19.

2. Kraft, B.A. Electrochemical Water Disinfection: A Short Review. Platin. Met. Rev. 2008, 52, 177-185, doi:10.1595/147106708X329273.

3. Mauter, M.S.; Elimelech, M. Enviromental application of cacbon- based nanomaterial. Environ. Sci. Technol. 2008, 42, 5843-5859.

4. Singh, S.P.; Li, Y.; Zhang, J.; Tour, J.M.; Arnusch, C.J. Sulfur-Doped Laser-Induced Porous Graphene Derived from Polysulfone-Class Polymers and Membranes. ACS Nano 2018, 12, 289-297. 
(C) 2020 by the authors. Submitted for possible open access publication under the terms and conditions of the Creative Commons Attribution (CC BY) license (http://creativecommons.org/licenses/by/4.0/). 